\title{
Process Design Method of High Speed and Stable Cutting Hardened Steel
}

\author{
Jiang Bin*, Zhang Minghui, Xu Tong and Zhang Wei
}

\author{
National \& Local United Engineering Laboratory of High Efficiency Cutting and Tools, Harbin University of Science \\ and Technology, Heilongjiang, Harbin, 150080, P.R. China
}

\begin{abstract}
In view of the unstable cutting problem in the process of high speed milling hardened steel. Conduct experiment of the stability of machine tool and high speed milling cutter. The machine tool spindle vibration spectrum and vibration acceleration signal under the condition of different centrifugal force were detected. Obtained the critical speed of security and stability cutting of milling cutter and machine tool spindle. Through the experiment of concave and convex surface of hardened steel high speed milling, obtained the vibration characteristic of machine tool spindle and the shape characteristic of machined surface of hardened steel concave and convex surface. Comparative analysis the experimental results of milling cutter free running and milling hardened steel under the same speed condition. Recognizing the significant effect of inherent vibration characteristics of machine tool to the stability of the hardened steel high speed milling. With the aim of achieving stable and efficient cutting of hardened steel, put forward process design method of high speed milling hardened steel. Using this process design method, obtained the process scheme of high efficient and stability cutting hardened steel die. Process validation results show, the stability of the high speed milling concave convex die of hardened steel improved over 33\%.
\end{abstract}

Keywords: Cutting stability, hardened steel, high speed milling, vibration of machine tool, vibration of milling cutter.

\section{INTRODUCTION}

The structure of automobile panel hardened steel die is complicated, surface hardness is uneven and the curvature distribution are all have a significant influence on high speed cutting process. The resulting unstable cutting problem becomes more complicated, has brought a greater difficulty for the high speed milling. The existing process data and design methods cannot satisfy the high efficiency and high quality needs of hardened steel die. So it is necessary to research in this aspect [1-3].

Existing research shows that, not only can shorten the processing cycle of die, improve the production efficiency, but also can guarantee the hardened steel die processing accuracy and surface quality by using high speed milling method to processing hardened steel die [4-6]. Therefore, domestic and foreign research institutions and related personnel through cutting experiment, the stability of the high speed milling process was studied, and to establish stability limit curve. Analyzes the single degree of freedom model of dynamic stability of high speed milling, the stability of main spindle system, the finite element model of the stability is established. Using semi-discrete method and approximating zero order method predicted the cutting stability limit of two degrees of freedom high-speed milling system. And put forward the rule of stability limit prediction [7-9]. The above related studies providing the basis for further study on high speed milling of hardened steel process design method.

At present, the most of high speed cutting stability studies are aiming at the single factor analysis, given unilateral cutting stability control method of machine tool and tool, but can not solve the problem of cutting stability under the influence of many factors. In the actual machining process, tool, machine tool and workpiece as a whole to influence the cutting stability of hardened steel [10]. The vibration effects of each part of the process system should be stacked to the tool vibration.

In this background, this paper in view of the above problems which were existed in the study of the high speed milling hardened steel cutting stability. Study the effect of the process variables on the stability of the high speed milling hardened steel, such as hardened steel surface curvature, hardness distribution, machine tool and tool safety stability, etc. Put forward the safe and stable cutting process design method of high speed milling hardened steel. Provide the basis and basic processing data to implementation the high efficiency, high precision and high surface quality of hardened steel die machining.

\section{MACHINE TOOL AND TOOL SAFETY STABILITY TEST}

For study the influence of dynamic performance of machine tool for cutting hardened steel high efficiency and stable. Experiment with high speed ball-end mills for free running stability test which are respectively installed on XH715 and UCP710 nc machine tools as shown in Figs. (1, 2). Among them, the diameter of coating carbide ball-end 
mill is $20 \mathrm{~mm}$. Extended length is $92 \mathrm{~mm}$, radial error of milling cutter is $0.01 \mathrm{~mm}$.

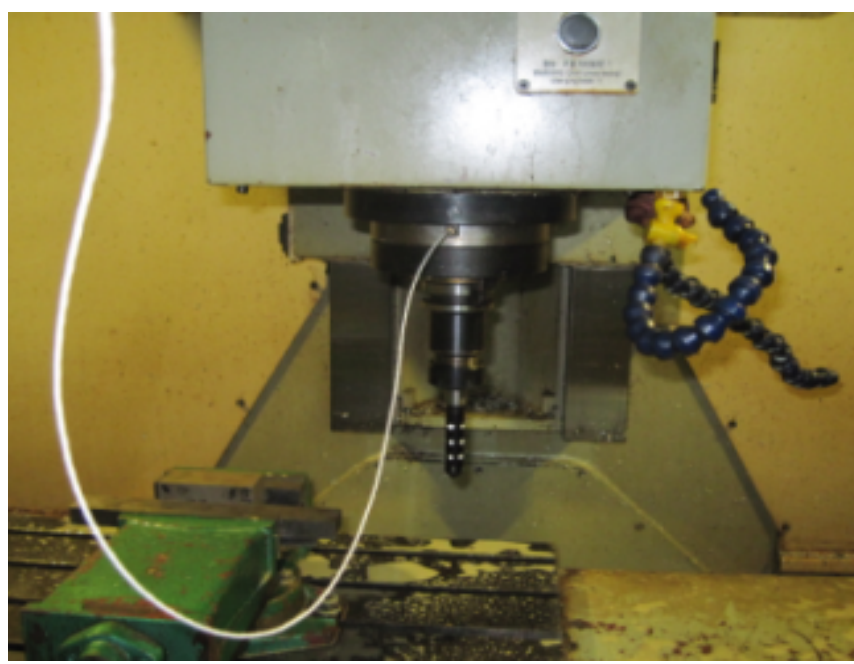

Fig. (1). Machine (XH715).

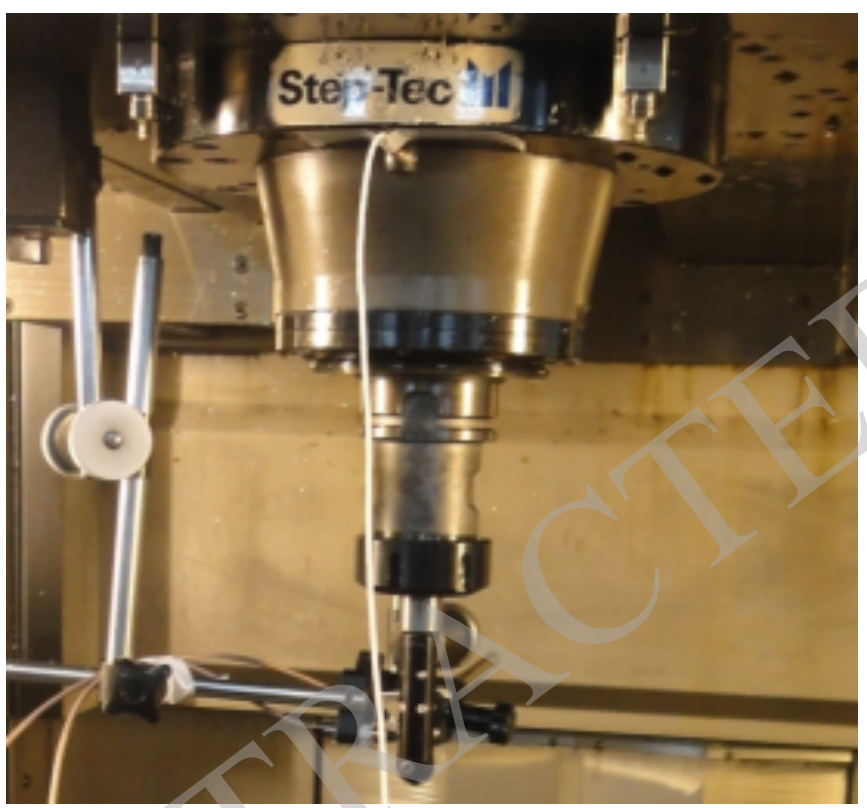

Fig. (2). Machine (UCP710).

Using eddy current displacement sensor and ICP acceleration sensor, extract spindle vibration acceleration signal and spectrum signal of the three-axis CNC milling machine $\mathrm{XH715}$, obtained the free running vibration characteristic curve of XH715 three-axis CNC milling machine tool spindle and milling cutter with diameter of 20 $\mathrm{mm}$ under the condition of $1000 \mathrm{rpm}-4000 \mathrm{rpm}$ speed as shown in Fig. (3).

The results of three-axis machine tool XH715 and cutter safety stability test experiment show that, using this machine tool machining hardened steel, affected by the machine tool high speed machining stability decline, the cutting speed of milling cutter security and stability is less than $3000 \mathrm{rpm}$. Under the condition of this speed, although the milling cutter vibration caused by the centrifugal force can be effectively restrain, but lower speed cannot satisfy the requirement of high efficiency cutting hardened steel.

Using the same test method, extract the spindle vibration acceleration signal and spectrum signal of five-axis machine tool UCP710. Obtained free running vibration characteristic curve of spindle of five-axis machine tool UCP710 and the milling cutter with diameter of $20 \mathrm{~mm}$, under the condition of $1000 \mathrm{rpm}$ to $2000 \mathrm{rpm}$ speed as shown in Fig. (4).

In the Fig. (4), speed increase from $1000 \mathrm{rpm}$ to 3000 $\mathrm{rpm}$, the vibration amplitude of machine tool spindle was increased linearly. When speed is in the range of $3000 \mathrm{rpm}$ to $10000 \mathrm{rpm}$, machine tool spindle vibration reaching steady. When the speed increased to the range of $10000 \mathrm{rpm}$ and $12000 \mathrm{rpm}$, spindle vibration decreases sharply along the axial, vibration is relatively stable along the row spacing and feed direction. At the same time, with the spindle speed increase, milling cutter vibration amplitude changes smaller. The experimental results show that the inherent vibration characteristics of machine tool and centrifugal force yibration caused by milling cutter error do not cause milling cutter stability decline. In this experiment speed range, the machine tool dynamics performance provides security for milling cutter cutting hardened steel efficient and stable.

\section{HIGH SPEED MILLING HARDENED STEEL MACHINE TOOL AND THE TOOL STABILITY}

According to above results, respectively using $\mathrm{XH} 715$ and UCP710 machine tools for high speed milling hardened steel convex and concave surface cutting stability experiment. Among them, the milling cutter uses coating hard alloy highspeed ball-end mill with diameter of $20 \mathrm{~mm}$, the cutting path is parallel. The hardness of hardened steel convex and concave surface specimen is HRC55 to HRC66. Along the feed direction, processing surface curvature radius is $65 \mathrm{~mm}$ to $1170 \mathrm{~mm}$. Along the row spacing direction machined surface curvature radius is $200 \mathrm{~mm}$.

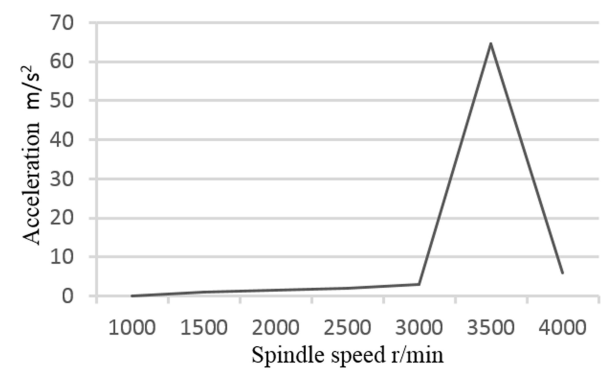

(a) Feed direction

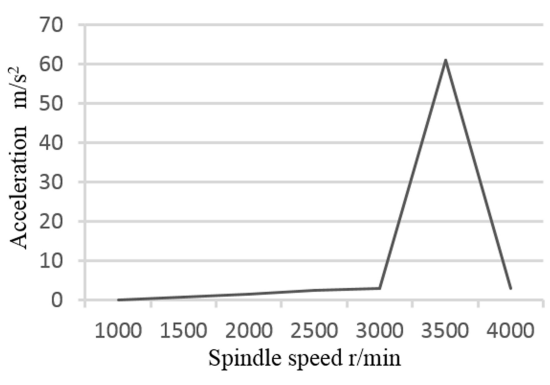

(b) Row spacing direction

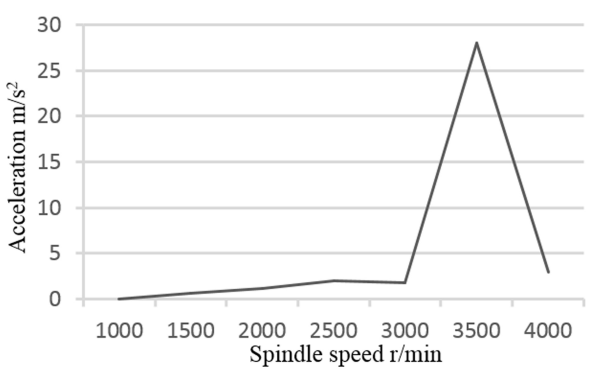

(c) Axial direction

Fig. (3). Vibration characteristic of XH715 machine. 


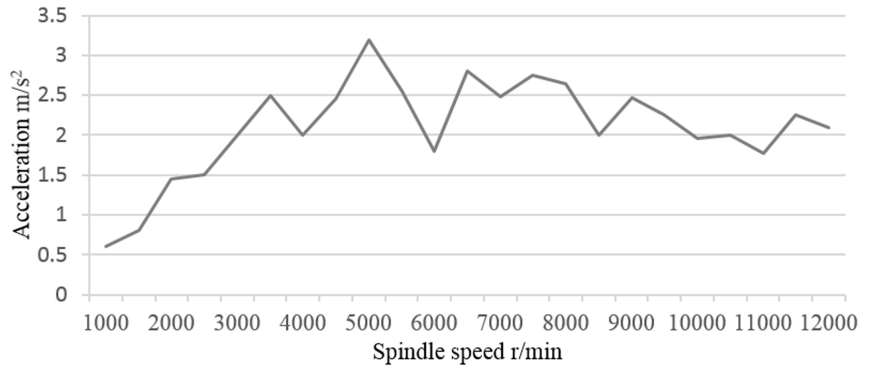

(a) Spindle vibration along direction of feed

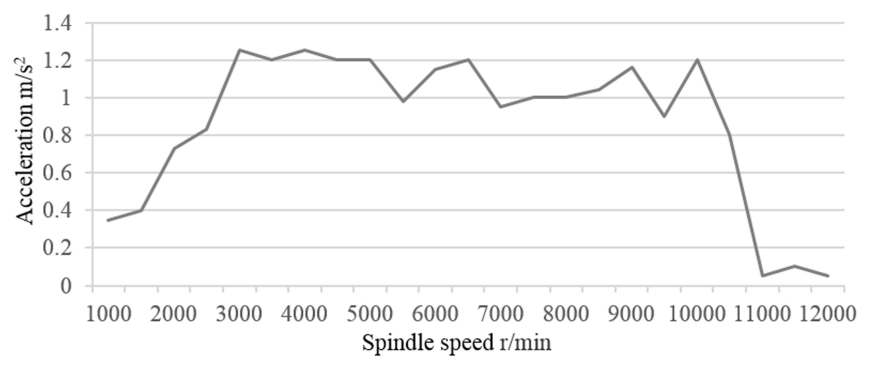

(c) Machine tool spindle vibration along axial

Fig. (4). Vibration test of machine and cutter (UCP710).

In the XH715 machine cutting experiment, the speed of milling cutter is $3000 \mathrm{rpm}$, feed speed is $1800 \mathrm{~mm} / \mathrm{min}$, row spacing is $0.3 \mathrm{~mm}$, back cutting depth is $0.2 \mathrm{~mm}$. In the UCP710 machine cutting experiment, the speed of milling cutter is $8000 \mathrm{rpm}$, feed speed is $4000 \mathrm{~mm} / \mathrm{min}$, row spacing is $0.3 \mathrm{~mm}$, back cutting depth is $0.2 \mathrm{~mm}$.

Using the high speed milling concave surface of hardened steel experiment, obtained machine tool spindle vibration test results is shown in Table 1 . The experiment results of hardened steel concave curved surface machining surface morphology is shown in Fig. (5).

Through the experiment of high speed milling hardened steel's convex surface, getting the test results of spindle vibration as shown in Table $\mathbf{2}$, and the experiment results of milled surface topography of hardened steel convex surface are shown in Fig. (6).

According to Tables $\mathbf{1}$ and $\mathbf{2}$, under the above experimental conditions, the cutting vibration of machine tool becomes most violent along the feed direction. When cutting hardened steel's convex and concave surface, UCP710 machine tool's spindle showed similar vibration characteristic, while the vibration characteristic of XH715 machine tool's spindle existed obvious differences. According to Fig. (6), the differences of speed and vibration characteristic of the two kinds of machine tool make its milled surface topography different obviously when cutting harden steel's surface.

Comparing with the experiment of cutter idling, analysis shows that when adopting XH715 machine tool cutting hardened steel's convex and concave surface, the spindle's vibration frequency is mainly uniformed with the cutter idling's vibration frequency. The dynamic performance of spindle directly determines the cutting states of high speed ball-end mill cutting hardened steel's surface and is influenced by concave and convex surface. The spindle's vibration amplitude shows a larger difference. Under this condition, the

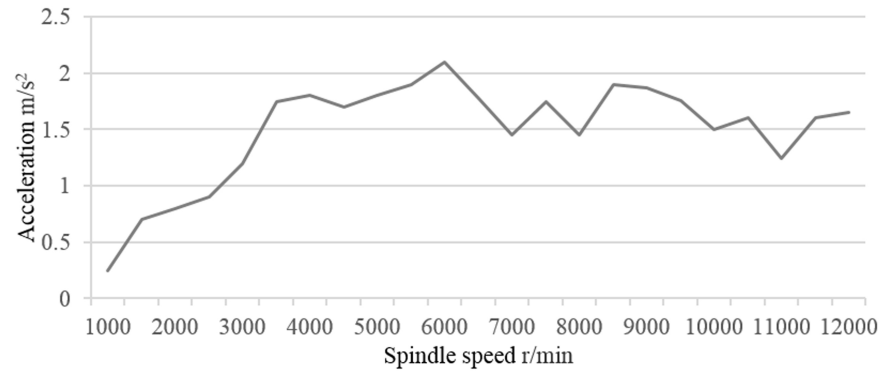

(b) Spindle vibration along leading direction

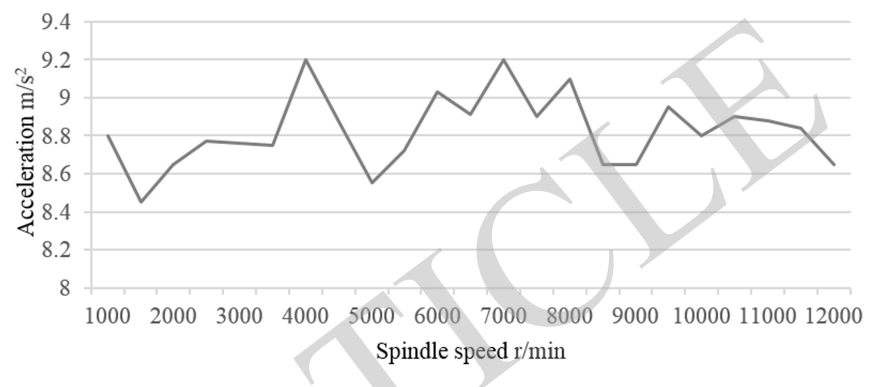

(d) Vibration of milling cutter

milled surface topography of hardened steel's convex and concave surface getting by the same cutting technology are obviously different.

Using UCP710 machine tool cutting hardened steel's convex and concave surface, the spindle's vibration amplitude frequency is lower than the cutter idling's vibration frequency evidently and basically stabilized at about $1600 \mathrm{HZ}$. And the change of hardened steel's convex and concave surface rarely effects on spindle and cutter's vibration. Under this condition, the milled surface topography of hardened steel's convex and concave surface getting by the same cutting technology have almost no difference.

The above results show that the influence of speed and cutting force on vibration characteristic is far less than the influence of the vibration of the machine tool itself when XH715 machine tool cutting hardened steel surface. While the vibration characteristic of UCP710 machine tool cutting hardened steel surface is mainly affected by speed and cutting force. Its dynamic characteristic has little influence on cutting states when high-speed ball-end mill cutting hardened steel surface

\section{STABLE SOLUTION CONDITIONS OF HIGH- SPEED MILLING HARDENED STEEL}

When using different machine tool to cut hardened steel surfaces, The vibration characteristics of the spindle have big difference on the impact of cutter cutting state. As such, during high speed milling of hardened steel surfaces stable cutting conditions for solving, at first, for the identification and evaluation of the affect for dynamic performance of machine as shown in Fig. (7).

On this basis, for the parts, machine tools, cutting tools and cutting parameters impact on the stability of high-speed 
Table 1. High speed milling hardened steel concave surface.

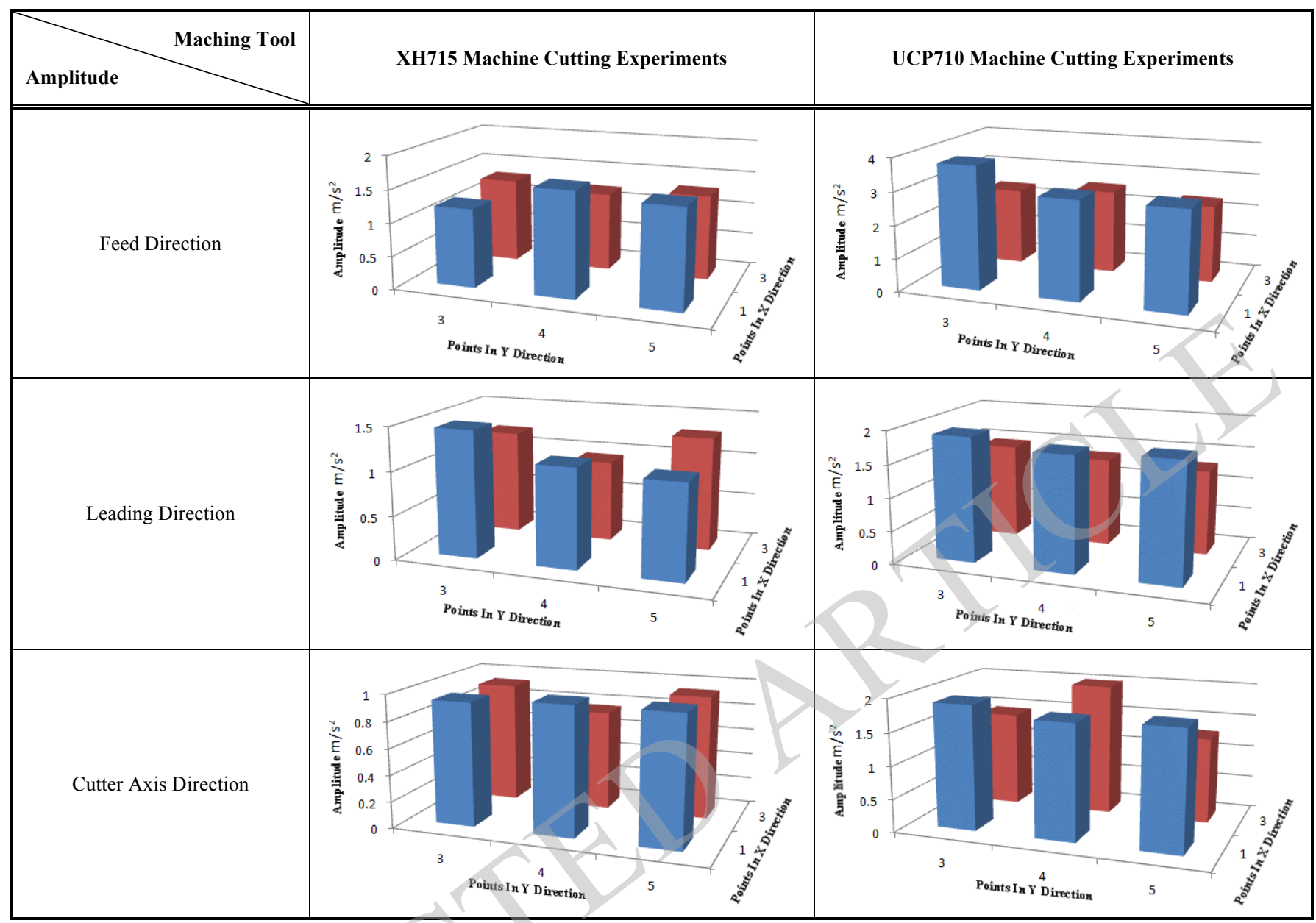

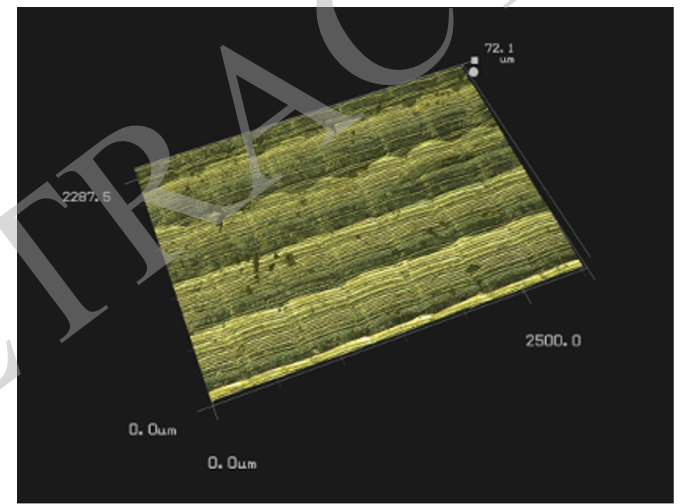

(a) Milled surface topography of XH715

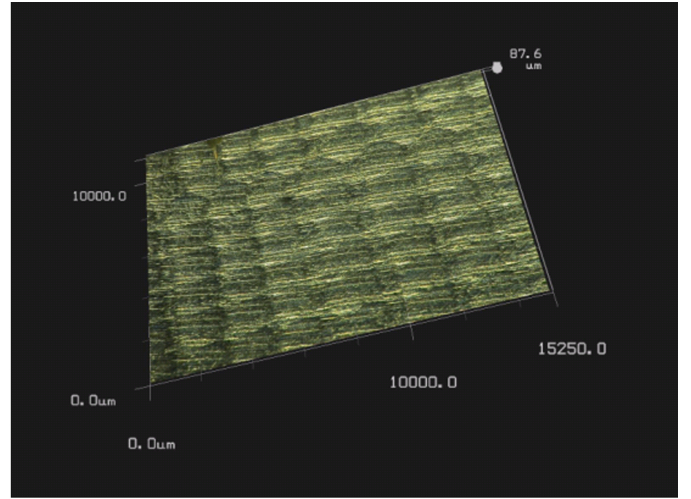

(b) Milled surface topography of UCP710

Fig. (5). Comparison of experimental result of concave surface.

milling, to achieve efficient and stable of cutting hardened steel, to get design goals of meet the processing efficiency and surface quality requirements, designing process of highspeed milling the hardened steel, the specific design flow shown in Fig. (8). In the figure, $f_{\mathrm{D}}$ is spindle vibration amplitude, $A_{1}$ is spindle vibration amplitude of security and stability of machine tool and tool, $f_{\mathrm{D}}$ is cutter vibration frequency, $f_{2}$ is cutter natural frequency, $\mathrm{A}_{\mathrm{M}}$ is multi-tooth of cutter cutting vibration amplitude, $\mathrm{A}_{2}$ is vibration amplitude of multi-tooth cutter for surface topography allowed, $A_{3}$ is vibration amplitude for efficient cutting, $\mathrm{A}_{4}$ is vibration amplitude for surface topography allowed.

This method takes into account machine tool, resonance, multi-tooth cutting, energy concentration, surface quality and other factors, to be bound and judge for hardened steel efficient cutting process, to obtain conditions of efficient and stable cutting hardened steel. 
Table 2. High speed milling hardened steel convex surface.

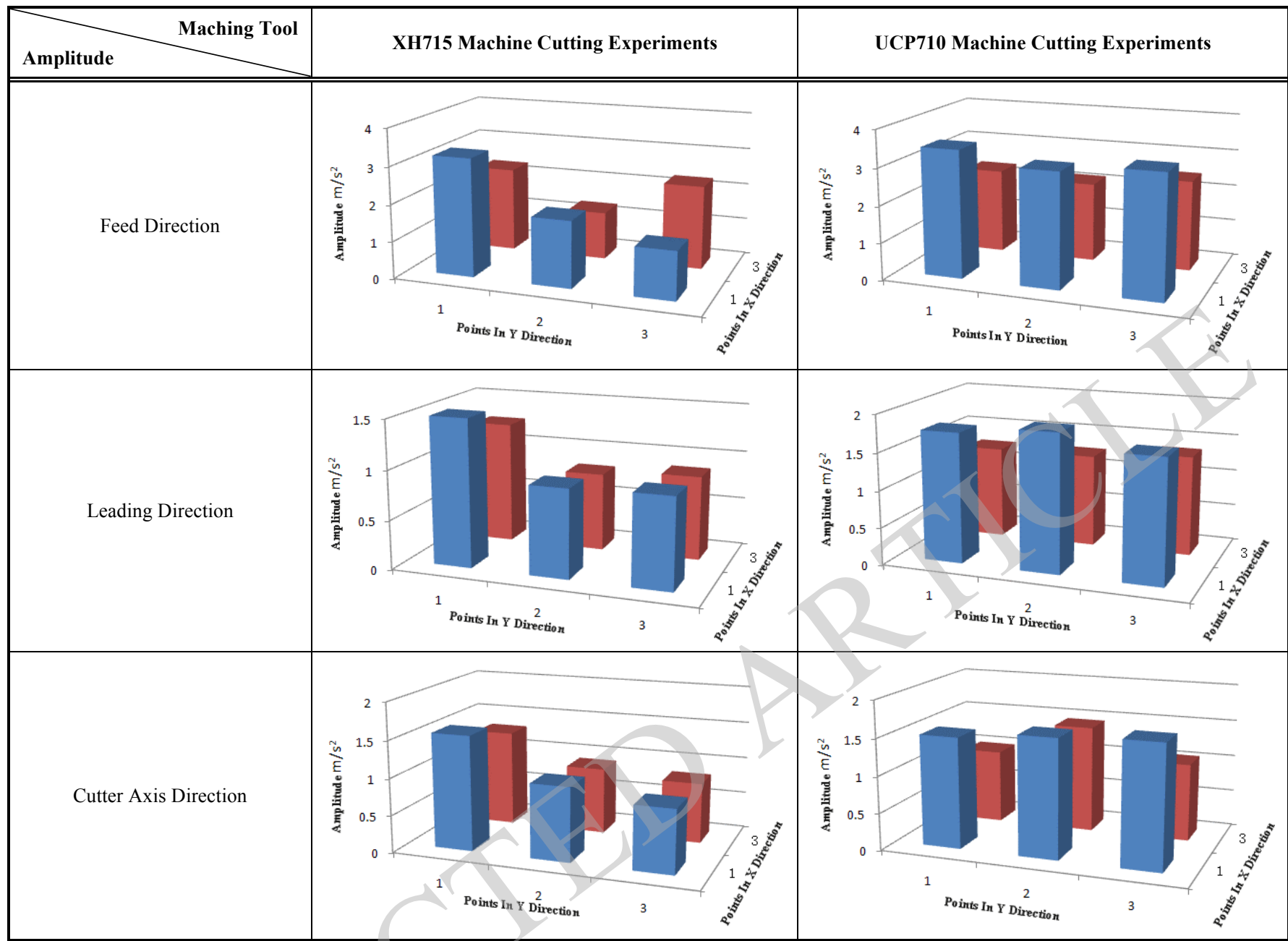

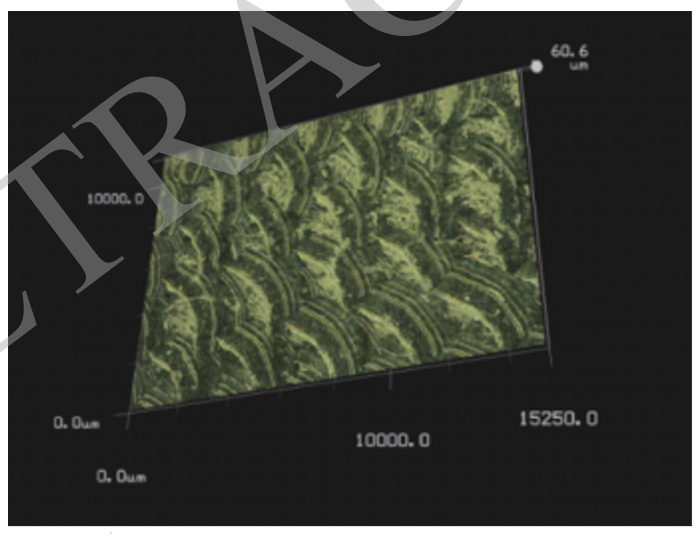

(a) Milled surface topography of XH715

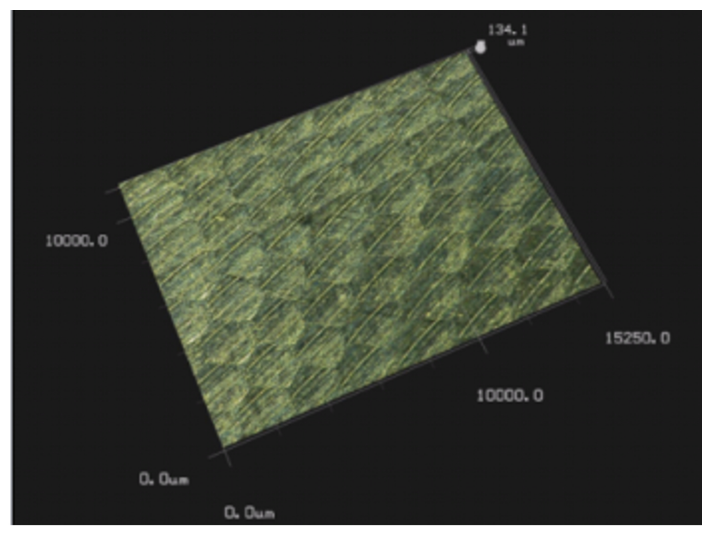

(b) Milled surface topography of UCP710

Fig. (6). Comparison of experimental result of convex surface.

\section{PROCESS EFFECT VERIFICATION OF CUTTING STABILITY ON HIGH-SPEED MILLING HARDENED STEEL'S DIE}

The die of inside covering parts of car uses $\mathrm{Cr} 12 \mathrm{MoV}$ hardened steel material whose hardness is HRC55 60. Its surface characteristic is complex and has many steep side and corner features. The original process adopted the ball- end mill whose diameter is $30 \mathrm{~mm}$. The speed is $4000 \mathrm{rpm}$, feed rate is $3000 \mathrm{~mm} / \mathrm{min}$, row spacing is $0.3 \mathrm{~mm}$, back cutting depth is $0.3 \mathrm{~mm}$. While when processing small curvature corner of die, the speed is $2000 \mathrm{rpm}$, feed rate is $1000 \mathrm{~mm} / \mathrm{min}$, row spacing is $0.3 \mathrm{~mm}$, back cutting depth is $0.2 \mathrm{~mm}$. The maldistribution of hardness and several variable of curvature lead to the cutter vibrating obviously during the process. 


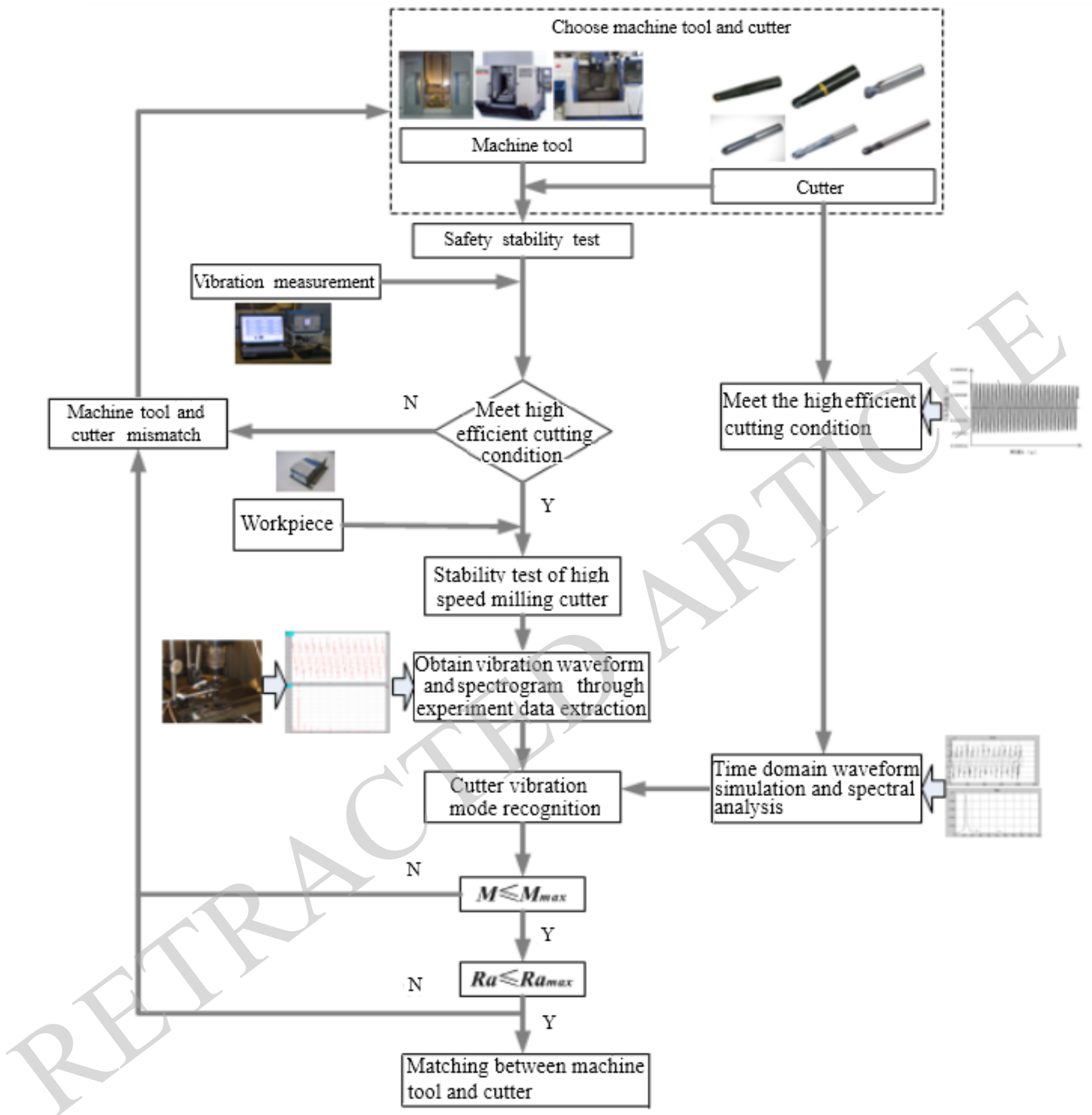

Fig. (7). Evaluation of machine tool dynamic performance.

To solve the above problems existing in high speed milling the die of inside covering parts of car, adopting the method of Fig. (7), recognising and evaluating the dynamic performance of machine tool when high speed milling the die of hardened steel, choosing five-axis gantry $\mathrm{CNC}$ milling machine of enterprises manufacturing the die of car's covering parts. Using the process design method of Fig. (8), solving the convex and concave die's efficient and stable cutting condition of this hardened steel's die, getting efficient and stable process scheme when cutting hardened steel's die. Among them, under the condition of cutting path invariant, adopting ball-end mill whose diameter is $20 \mathrm{~mm}$. The process conditions of cutting hardened steel's die as follows: the speed is $6000 \mathrm{rpm}$, feed rate is $4800 \mathrm{~mm} / \mathrm{min}$, row spacing is $0.3 \mathrm{~mm}$, back cutting depth is $0.2 \mathrm{~mm}$. And when processing small curvature corner of die, the speed is $6000 \mathrm{rpm}$, feed rate is $2000 \mathrm{~mm} / \mathrm{min}$, row spacing is $0.3 \mathrm{~mm}$, back cutting depth is $0.2 \mathrm{~mm}$.

The effect comparison of cutting stability of old and new process when high-speed milling hardened steel's die is shown in Fig. (9). Analysis results show that compared with 


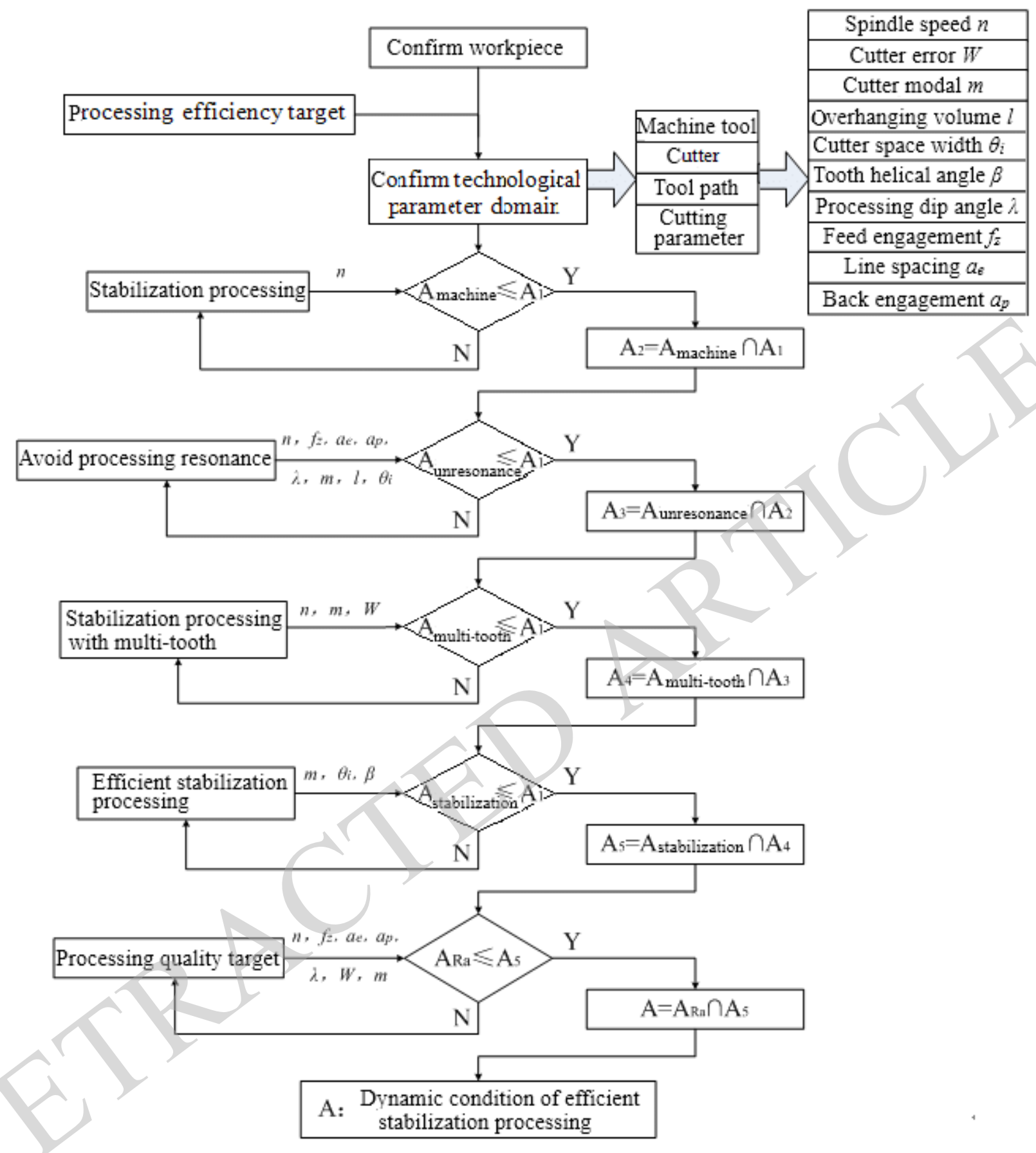

Fig. (8). Process design process of efficient and stable cutting.

the original process, the efficient cutting stability of bedding face processing of hardened steel's die increases by $33 \%$ $60 \%$. At the corner, it is increases by $104 \%$.

\section{CONCLUSION}

The test results of machine tool and cutter show that speed increases exponentially only changes the cutter's centrifugal force main frequency of vibration and does not cause the cutter's centrifugal force vibration amplitude increasing significantly. The cutter's centrifugal force vibration has no significant effect on high-speed stable cutting speed.
The machine tool's inherent vibration characteristics directly determines the speed range of high-speed milling stability.

The experiment of high-speed milling hardened steel's convex and concave surface shows that when there is a good dynamic performance matching relationship between machine tool and cutter, the spindle's vibration frequency is lower than that of cutter idling and in a stable state. The change of hardened steel's convex and concave surface has little influence on spindle and cutter's vibration. Under this condition, the milled surface topography of hardened steel's convex and concave surface getting by the same cutting technology have almost no difference. 


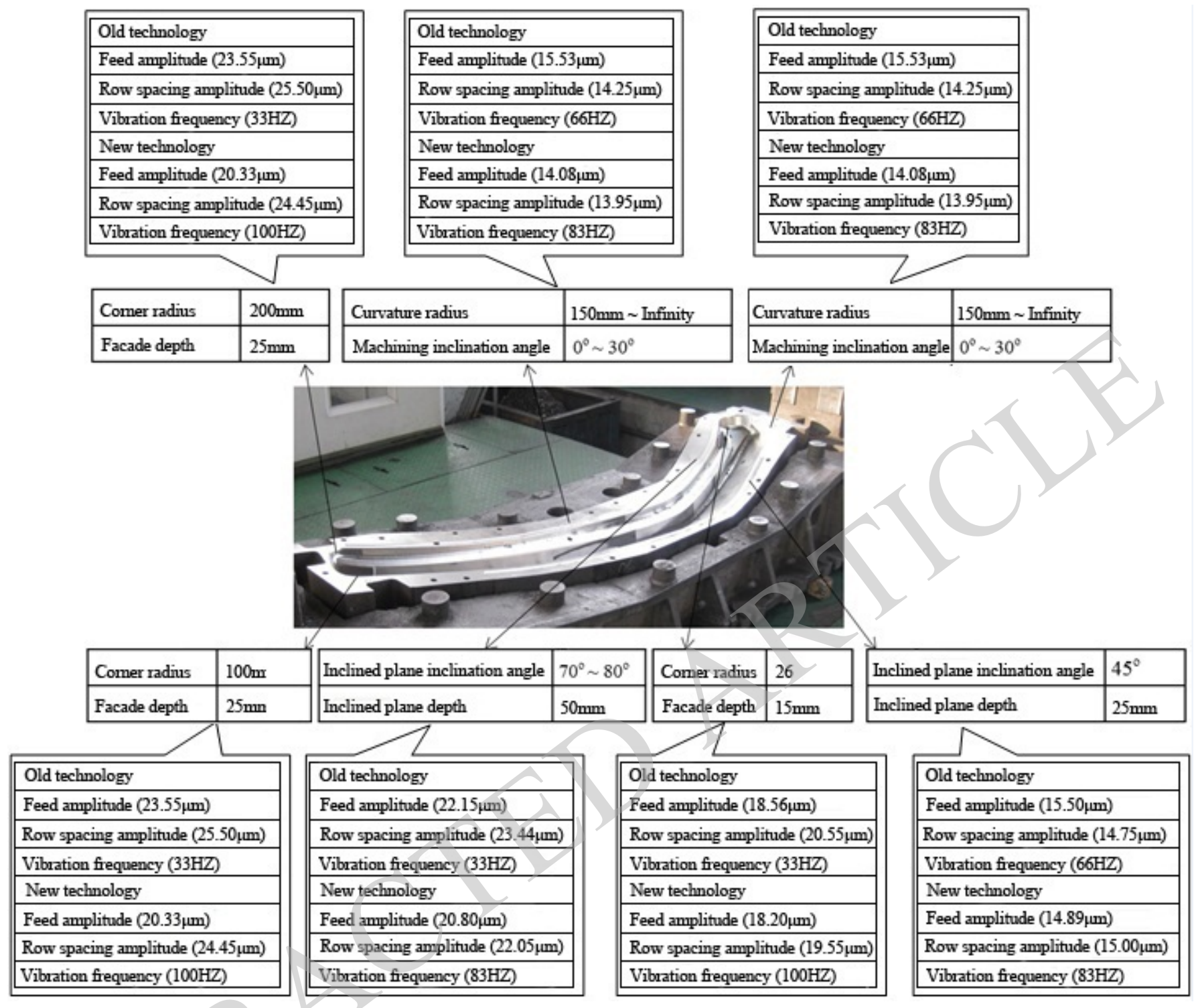

Fig. (9). Technics analysis of stability.

Proposing the process design method of high-speed milling hardened steel's convex and concave surface. The method uses the dynamic performance recognition and evaluation results of machine tool, comprehensive considers the factors such as machine tool, resonance, multi-tooth cutting, energy concentration, machined surface quality, and so on. Through judging and restraining process domain of high-speed milling hardened steel, getting the process scheme of high-speed stability cutting hardened steel.

Adopting this process design method, getting the high speed cutting process of hardened steel's die of the car's inner cover parts. Comparing with the original process, the efficient cutting stability of bedding face processing of hardened steel concave's die increases by $33 \% \sim 60 \%$. This process design method effectively solve the die's type surface complex and instability cutting problem caused by steep side and corner feature varying in high-speed milling hardened steel's die.

\section{CONFLICT OF INTEREST}

The authors confirm that this article content has no conflict of interest.

\section{ACKNOWLEDGEMENTS}

This work was supported by National Natural Science Foundation of China (51375124).

\section{REFERENCES}

[1] C.Y. Wang, Z. Qin, and S.X. Wu, "High speed milling of hardened steel for die \& mold", High-speed High Precision Machining and Die Manufacturing Technology, vol. 3, pp. 27-31, 2009.

[2] A. Liu, C. Peng and J.Z. Liu, "The prediction of flutter's vibration and stable processing area when high-speed milling", Chinese Journal of Mechanical Engineering, vol. 43, pp. 164-168, 2007. 
[3] W.L. Weingaertner, P.B. Schroeter, and M.L. Polli, "Evaluation of high-speed end milling dynamic stability through audio signal measurements", Journal of Materials Processing Technology, vol. 179, pp. 133-138, 2006.

[4] T. Insperger, B.P. Mann, G. Ste'pa'n, and P.V. Bayly, "Stability of up-milling and down-milling", International Journal of Machine Tools \& Manufacture, vol. 43, pp. 25-34, 2008.

[5] S. Smith, and J. Tlusty, "Current trends in high-speed machining", Journal of Manufacturing Science and Engineering, vol. 119, pp. 664-666, 2010.

[6] G. Janez, and K. Malveram, "On stability prediction for milling", International Journal of Machine Tools \& Manufacture, vol. 45, pp. 769-781, 2005.
[7] Z.Q. Li, and Q. Liu, "Impact of modal parameters on milling process chatter stability lobes", Journal of Wuhan University of Technology, vol. 28, pp. 190-195, 2006.

[8] Z. Qin, C.Y. Wang, Y.S. Lin, and Y.N. Hu, "Optimisation of tool angles and the relation between tool path and cutting force in highspeed milling with micro-end-mill", International Journal of Computer Applications in Technology, vol. 28, pp. 20-26, 2007.

[9] C.K. Toh, "Cutter path orientations when high-speed finish milling inclined hardened steel", International Journal of Advanced Manufacturing Technology, vol. 27, pp. 473-480, 2006.

[10] Z. Aksoy, Y. Gür, and I. Erenr, "High-speed milling strategies in mould manufacturing", International Journal of Materials Research, vol. 101, pp. 431-438, 2010.

(C) Bin et al.; Licensee Bentham Open.

This is an open access article licensed under the terms of the Creative Commons Attribution Non-Commercial License (http://creativecommons.org/licenses/by-nc/3.0/) which permits unrestricted, non-commercial use, distribution and reproduction in any medium, provided the work is properly cited. 